\begin{tabular}{|l|l|l|l|l|}
\hline Profile & S-M Ho & $\begin{array}{l}\text { Against the odds: how to make } \\
\text { it work? }\end{array}$ & 21:4 P19-P24 \\
\hline
\end{tabular}

\title{
Battle against the odds: win with effort, attitude, and perseverance!
}

\author{
Shuk-Mei Ho $\mathrm{Ho}^{1,2,3}$ \\ ${ }^{1}$ Department of Environmental Health and Center for Environmental Genetics, University of Cincinnati \\ College of Medicine, Cincinnati, Ohio, USA \\ ${ }^{2}$ Cincinnati Cancer Center, Cincinnati, Ohio, USA \\ ${ }^{3}$ Cincinnati Veteran Affairs Medical Center, Cincinnati, Ohio, USA
}

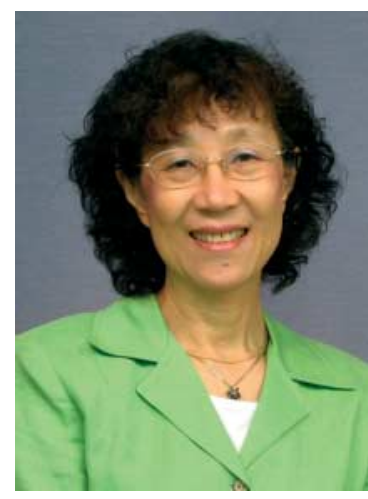

Correspondence

should be addressed

to S-M Ho

Email

hosm@ucmail.uc.edu

Growing up female in colonial Hong Kong during the late 1960s meant limited opportunities for a career. Household chores and part-time jobs after school filled up the days. The lack of role models also limited my early vision. To this end, I owe my academic career to my parents, who never finished high school due to the Second World War but believed in the value of a college education, not just for their son but also for their first-born daughter!

I always wanted to be a physician. I trapped sewer rats and household cockroaches to practice on dissection. I sneaked into physics laboratory after school to get extra practice on wiring electrical circuits. Yet, in a system, where the acceptance rate to universities was $<2 \%$ and the distribution of students into majors was based on grades, I was extremely lucky to be accepted to one of the top universities in Asia, the University of Hong Kong, majoring in biological sciences. Sometimes, I do wonder what if I had gone into medicine...then I would likely be a multimillionaire physician practicing in Hong Kong instead of a scientist in USA.

In the early 1970s, the political arena in China was filled with turmoil; drastic social changes happened in Hong Kong. As a college student, like many of my peers, I spent most of my time engaging in student movements and staying up all night debating issues that mattered to society. These events took deep roots in my young mind, allowing the core value of contributing to society to grow inside me as the years passed by. Surprisingly, or luckily, I managed to graduate with a First-Class Honor and earned a full scholarship to pursue a PhD degree in Zoology at the university.

My thesis mentor, Daniel Chan, was a rising star just returned from Sheffield University, England. Not only was my training in the physiology of the Japanese eel (Anguilla japonica) vigorous, but also I was constantly challenged by his tough comments, such as 'Working hard is not enough, one must work smart' and 'Learners must take responsibility of learning'. There were never empty praises or warm fuzzy feelings from Dr Chan. I learned to take to heart the hard criticisms and make good use of them. It was only after years that I recognized how heavy-handed patriarchy impedes a woman's growth; I am thankful being spared of it in my early upbringing and after graduate school.

I put in many $14 \mathrm{~h}$ days to finish my $\mathrm{PhD}$ in 3 years, just to be confronted with the hard reality: getting a faculty position at a university in Hong Kong was next to impossible for a female doctoral graduate. To fix my shattered dream, a stouthearted decision was made to depart for post-doctoral training with Dr Ian Callard, a comparative endocrinologist, at the Biology Department, Boston University. Arriving Boston in August 1977, I was welcomed by over 27 inches of snow during the historical Northeastern United States blizzard in February 1978.

Published by Bioscientifica Ltd 
The city was under curfew but I was determined to walk $2 \mathrm{~h}$ back to the laboratory to safeguard an experiment. The power went off that night and I spent the night sleeping on a laboratory bench with a pile of laboratory coats just to keep warm. Although I was promised a faculty position after 1-year of training, it never happened. By the end of the second year, I knew there was no point looking back; I had to build a career in USA. In a way, I was extremely fortunate to have landed in Boston, one of the world's most vibrant learning communities, for my journey.

My project was to isolate the egg yolk protein vitellogenin from the eastern painted turtle, Chrysemys picta, and develop a RIA for it. Vitellogenin is made in the liver of female vertebrates under the control of estrogen and packaged into the egg yolk supporting embryo development in all egg-laying vertebrates. This was considered as a 'hot' topic in comparative endocrinology as Rosalyn Yalow had just received the 1997 Nobel Prize in Medicine for the development of a RIA for human insulin (Yalow \& Berson 1960). As our supply of turtles was unreliable, we often went out to trap turtles in the rivers around Boston. Occasionally, a snapping turtle was trapped and turned our trip into an adventure, as we struggled to get it out of the trap avoiding loss of fingers. Within a year, we had a specific RIA for turtle vitellogenin (Gapp et al. 1979) and were able to study hormonal regulation of turtle vitellogenesis.

One amazing finding I did not publish then was the observation that male turtles had low levels of vitellogenin expression. At that time, we attributed this to low levels of endogenous estrogen in the males. Now, compelling evidence supports the theory of endocrine disruption. Vitellogenin expression in the male turtles was probably caused by exposure to environmental estrogenic mimics present in the Charles River and its tributaries. This finding marked the beginning of my career in endocrine disruption. It also coincided with the emergence of the field (Colborn et al. 1993). Many star researchers were born. Over the years, I had the good fortune to make acquaintance with many, including Scott Belcher, Linda Birnbaum, David Crews, Theo Colborn, Michael Gallo, Louis Guillette, Jerrold Heindel, Patricia Hunt, Kenneth Korach, George Lucier, John McLachlan, John Peterson Myers, Retha Newbold, Gail Prins, Beverly Rubin, George Stancel, Carlos Sonnenschein, Ana Soto, Shanna Swan, Frederick vom Saal, Cheryl Walker, Cheryl Watson, Wade Welshons, Mary Wolfe, and Thomas Zoeller, and have shared a lifetime of passion with them.

As a foreign-born postdoc in the laboratory, I was terrified whenever the phone rang. Without body language and eye contact, it was hard for me to be understood by the party at the other end of the line. I quickly recognized that this handicap would cripple my career advancement. A disciplined plan was implemented to lose my British/Chinese accent and expand my vocabulary. Going to Red Sox games at Fenway Park with my labmates, watching the Cowboys-Steelers rivalry unfold in our living room, and learning cultural diversity through parties celebrating ethnic holidays were parts of this immersion strategy. Additional exposure was gained when our laboratory traveled to the Mount Desert Island Biological Laboratory in the summer for marine research, allowing a unique exposure to the simple, rural Maine culture.

Ian was a generous mentor. Within months of my training, he started letting me make his presentation slides. This was the pre-PowerPoint era when everything was done with drawing pens and sticky labels, and slides were made in a dark room using a camera and a developer. This training proved invaluable. I learned how to connect concepts to data and select key messages to support conclusions, producing visually and scientifically impactful presentations. Soon after, Ian began sending me to present at national and international meetings whenever he had a conflict. I traveled to present at places such as Bern (Switzerland), Nashville (Tennessee) and Mont Tremblant (Quebec), where I was exposed to giants in the field of hormone action and hormonal carcinogenesis. These opportunities broadened my vision, enhanced my confidence, and allowed networks to be built.

I was very lucky to be recruited to the Biology Department at Tufts University as a tenure-track assistant professor in 1980. My teaching responsibilities included Endocrinology, Human Reproduction, and various senior seminar classes. I also taught a section on reproductive physiology for the medical, dental, and veterinary students. This teaching load was heavy considering that I was always holding one to two federal grants as a principal investigator. Additionally, I had over 80 advisees in any given year; most of them majoring in pre-med, pre-dental, pre-law, or engineering. The undergraduate students at Tufts are extremely bright and I routinely had four or five of them working in the laboratory. Many of the papers I published during my tenure at Tufts had more than one of them as coauthors. The mentoring experience was both educational and rewarding. Benjamin Franklin once remarked: 'Tell me and I forget, teach me and I may remember, involve me and I learn'. This quote summarizes the value of involving young talents early in their lives. Many of them are now leaders in their fields, such as Henry

Published by Bioscientifica Ltd. 
Seto, MD, Vice President for Global Patient Safety at Vertex Pharmaceuticals, Douglas M Press, JD, Senior Assistant Attorney General, State of California, and Jeffrey Ziar, DMD, Ziar Dental, PC, New York.

Research was always emphasized at this prestigious undergraduate teaching university. From my third year onward, I was funded continuously by federal grants. My research took a turn and began its transition from comparative endocrinology to prostate cancer when I met two of my mentors and lifetime collaborators, Dr Irwin Leav, a pathologist, and Dr Peter Ofner, a steroid biochemist. We worked closely to establish and grow a research project entitled 'Prostatic Differentiation and Sex Hormone Metabolism' for 30 years. Peter passed the principal investigatorship to Irwin who passed it on to me. The primary goal of the grant was to understand how steroid hormones contribute to prostate carcinogenesis. My early work on estrogen action in vitellogenesis redirected the project from one focusing only on androgen action to a new hypothesis proposing that estrogen, supported by androgen, and drives prostate carcinogenesis. Our hypothesis was inspired by early epidemiological studies of Brian Henderson, Ronald Ross, Leslie Bernstein, and Malcolm Pike at the University of Southern California showing higher levels of estrogens in African American men when compared with their Caucasian counterparts (Ross et al. 1986), which may explain the higher prostate cancer incidence in Black Americans. More recent epidemiological studies conducted by Elizabeth Platz, William Nelson, and their colleagues at Johns Hopkins (Rohrmann et al. 2007) have provided further support to this posit.

We developed a model using Noble rats in the late 1980s (Ho et al. 1988, Leav et al. 1988) to test this hypothesis. Chronic treatment of this hormonally sensitive strain with estrogen, under the support of androgen, induced $\sim 100 \%$ of high-grade prostatic intraepithelial neoplasia (PIN). The model has direct human relevance as our collaborators John McNeal and David Bostwick just reported intraepithelial dysplasia (PIN) as a purported pre-lesion of human prostate cancer (McNeal \& Bostwick 1986). This model also allowed us to interact with many renowned researchers who had developed various experimental models for prostate cancer research. These included models from Marteen Bosland, Leland Chung, Jerry Cunha, Norman Greenberg, John Isaacs, Dona Peehl, and Timothy Thompson. The models also facilitated robust preclinical trials of various dietary agents for prostate cancer prevention. Some of the findings were successfully translated into clinical trials by colleagues including Stephen Clinton, Ian Thompson, David
Crawford, Marteen Bosland, and George Wilding on genistein, lycopene, soy isoflavones, vitamin E, vitamin D, and selenium.

I began serving on study sections and received invitations to speak after I earned tenure in 1986. These were great networking opportunities. I learned from my senior colleagues that one must be 'over-prepared' for these professional activities. Hence, for each study section, instead of reading my critiques verbatim, I wrote and practiced on a much shorter version of the critique that captured the essence of the full version. The ultimate goal was to present all the arguments with full command of the contents in the proposal as if one had written it. A reviewer's job is to advocate for the applicant in his or her absence. In meetings, I always had the feeling that I was the only one not knowing a soul. Soon, it became apparent that many of the participants were in the same situation. To make the best of the opportunity, it is up to oneself to initiate conversation to break the ice. During the prebusiness card and pre-email period, I spent a huge amount of effort on pre-meeting preparation and follow-up letters to ensure that a contact was established. Meticulously, I created a 'super rolodex card system' to manage these invaluable contacts and networks. These contacts are highly selective and therefore, once established, can last a lifetime. This is in stark contrast with the current electronic era, in which we are bombarded with emails and unsolicited information every minute. The impulse to respond instantly disrupts attention and detracts from productivity. One possible solution to manage information overload is to set aside time and limit the time allotted to read and respond. This is more easily said than done, however, as most of us worry about missing that one important message.

Balancing family and workplace demands is always hard if not impossible in academia. A faculty member is supposed to achieve excellence in teaching, research, and service. From 1985 to 1990, I had three 'invisible births', which were quite common for women faculty in those days. It meant working on a manuscript till labor started, no maternity leave, and never missing a meeting because one of the children was sick. On one hand, motherhood is the greatest joy and accomplishment in life. On the other hand, that time was truly stressful. I worked every minute to provide quality time for each of my children. But at times, the balancing act tumbled. For example, one summer afternoon as I walked out of my office, I panicked because I had forgotten which babysitter (out of seven) I had dropped off my youngest child. My heart raced as I searched through my head for the lost information. At

Published by Bioscientifica Ltd. 
Tufts, we had a wonderful group of female leaders, deans, and chairs, who served as role models. But it was still a small miracle that I was able to establish my academic career against these challenges. I owe this small triumph to a group of influential women on campus, including Nancy Milburn, Mary Ellen Feinleib, Susan Ernst, June Aprille, Elizabeth Ammons, Susan Ostrander, Frances Chew, and Marilyn Glater. It was a joy growing up in a nurturing environment that supported career development and personal growth!

I rose through the academic ranks and attained full professorship in 1995. In addition to being a highly dedicated educator and a successful researcher, I also excelled in service and administration. I learned to put together cross-disciplinary and cross-functional teams to start new programs. Worthy of mention are three crosscollege, cross-campus institutes that I helped build: the Women's Programs, the Tufts Institute for the Environment, and the Tufts Institute for Leadership and International Perspectives (now the Institute for Global Leadership). In 1997, I was appointed Associate Dean for Research, School of Graduate Studies, Research and Continuing Education. I was the highest administrative official responsible for the research support infrastructure on the University's main campus with 340 full-time faculty members and $\$ 18$ million in research funds.

Recognizing the limits to clinical and translational collaboration, I accepted an offer in 1999 to become the Director of Urological Research at the University of Massachusetts Medical Center, where we could work closely with urologists, residents, and fellows. We attended weekly prostate cancer tumor board and received a small gift to set up a tumor bank. With the help of our clinical collaborators, we completed four clinical trials for the discovery of prostate cancer biomarkers including a study of alpha-methylacyl-CoA racemase transcripts in sediments of urine samples and the use of high-throughput mass spectrometry for the discovery of metastasis-predicting protein markers. The proximity to and the embedding structure of a basic science laboratory in a clinical department were driving forces for the success of our research transition. This also coincided with the establishment of the Department of Defense Prostate Cancer Research Program (PCRP), established in 1997, to promote innovative translational research outside the more traditional realm of the NIH. In 8 years, we established a nationally renowned program in translational research for prostate cancer with multiple awards from the PCRP and the National Institutes of Health. My active participation in the PCRP program allowed me to interact with some of the most amazing warriors fighting this disease, including Stephen Balk, Angela Brodie, Ching-Shih Chen, Ralph deVere White, Hsing-Jien Kung, Natasha Kyprianou, Massimo Loda, James Mohler, Trevor Penning, Gail Prins, Timothy Ratcliff, Howard Soule, Mary-Ellen Taplin, Zhou Wang, Stephen Plymate, Marianna Sadar, and Janet Stanford.

Studying estrogen in prostate cancer has never been easy (Ho et al. 2011). First, the prostate gland is always perceived as an androgen regulatory organ. Secondly, the traditional dogma for decades was that cancer results from an accumulation of multiple mutations caused by the genotoxic effects of carcinogens. Estrogens were and are not recognized as having major genotoxicity. Hence, at one point, a fierce debate was focused on whether the carcinogenetic action of estrogen is due to its genotoxicity or receptor action (Cavalieri et al. 2000). I was glad to be included as a novice in this debate and had benefited significantly through regular meetings with key thought leaders including Leon Bradlow, Ercole Cavalieri, Krystyna Frenkel, Joachim Liehr, Eleanor Rogan, Sarah Antoni Li, Johnathan Li, David Longfellow, Suresh Mohla, Satyabrata Nandi, Deodutta Roy, Jose Russo, Richard Santen, and Thomas Sutter. This group mainly focused on debating estrogen action in breast cancer. To my credit, I stayed loyal to my quest and kept searching for the mechanism underlying the action of estrogen in the prostate.

The landmark discovery of a second estrogen receptor, estrogen receptor $\beta$ or ESR2 (Kuiper et al. 1996), which is highly expressed in the prostate, by Jan-Ake Gustafsson was a turning point in my quest. With Irwin Leav and a new postdoc, Xuegong Zhu, we conducted a painstaking study using laser capture microscopy and bisulfite sequencing of clinical specimens to interrogate DNA methylation and receptor expression down to single tissue level (Zhu et al. 2004). We reported the reversible epigenetic regulation of ESR2 expression in the prostatic epithelium as it turns into pre-cancerous lesions, cancer, and finally bone metastasis. After 2 years, with my talented colleague, Yuet-kin Leung, we reported the cloning of isoforms 2, 4, and 5 of the human ESR2 (Leung et al. 2006). These findings jump-started the field searching for new functions of these isoforms. They have very low binding affinity for the traditional ligands and can serve as coregulators for ESR1. However, of great interest is the fact that they have expression patterns and cancerregulatory functions that are markedly different from ESR1. The verdict is still out and the pace is picking up in this new field.

Published by Bioscientifica Ltd. 
Collaboration and cross-fertilization of ideas are critical to innovative science. In the same year, together with my long-term collaborator, Gail Prins, and an exceptional postdoc, Wan-yee Tang, we reported that neonatal exposure to estrogens such as $17 \beta$-estradiol and the ubiquitous environmental endocrine disruptor, bisphenol A, causes a long-term change in cancer susceptibility in the adult prostates of Sprague-Dawley outbred rats (Ho et al. 2006). Importantly, this early-life reprogramming effect correlated with permanent changes in methylation marks and gene expression pattern in the adult prostate gland. This breakthrough research contributed to the emerging field of epigenetics as a mechanism of Developmental Origins of Health and Disease (DOHaD). It also established epigenetics as the 'bridge' between genetics and the environment. Professionally, it was perfect timing as I had just started as Chair and Jacob G. Schmidlapp Professor at the Department of Environmental Health, University of Cincinnati Medical Center and renewed a National Institute of Environmental Health Sciences-funded Center for Environmental Genetics. It helped my transition back to the field of endocrine disruption and enabled me to move into epigenetic studies, not just for cancer but also for other complex diseases. For the research community, this line of investigations has sparked a paradigm shift from viewing genetics as the root cause of all diseases to an expanded view of genetic-epigenetic interaction controlling disease susceptibility, human health, and perhaps population drifts. I feel honored for my small contribution in DOHaD and epigenetic epidemiology and remain extremely excited about future research opportunities in these fields. My intermediate-term passion is to add evidence to the potential trans-generational effects of epigenomics in disease and health. I must mention that the works of Randy Jirtle, Michael Skinner, Frederick Perera, and Peter Gluckman have heavily influenced mine. While Randy Jirtle just received the Twinthieth Linus Pauling Functional Medicine Award (May 2014), I am still yearning for a membership in the Institute of Medicine.

At this stage of my career, I have the experience and the capital to help young talents realize their dreams. Hence, one of my most gratified recent awards was the 2013 Mentor of Excellence Award from Prostate Cancer Foundation because the nominee was a brilliant young woman, Hung-Ming Lam, now a faculty at the University of Washington. My commitment toward this runs deeper than the Kali Gandaki Gorge in the Himalayas.
Overall, my research, like life, seems to come full circle. Ironically, the attitude of success in both appears to lie midway between the sage view of William Shakespeare 'It is not in the stars to hold our destiny but in ourselves' and the wise teaching of Taoism 'Wu-wei' or 'the Action of Non-Action'.

\section{Declaration of interest}

The author declares that there is no conflict of interest that could be perceived as prejudicing the impartiality of this profile.

\section{Funding}

This profile did not receive any specific grant from any funding agency in the public, commercial or not-for-profit sector.

\section{References}

Cavalieri E, Frenkel K, Liehr JG, Rogan E \& Roy D 2000 Estrogens as endogenous genotoxic agents - DNA adducts and mutations. Journal of the National Cancer Institute. Monographs 27 75-93. (doi:10. 1093/oxfordjournals.jncimonographs.a024247)

Colborn T, vom Saal FS \& Soto AM 1993 Developmental effects of endocrine-disrupting chemicals in wildlife and humans. Environmental Health Perspectives 101 378-384. (doi:10.1289/ehp. 93101378)

Gapp DA, Ho SM \& Callard IP 1979 Plasma levels of vitellogenin in Chrysemys picta during the annual gonadal cycle: measurement by specific radioimmunoassay. Endocrinology 104 784-790. (doi:10.1210/ endo-104-3-784)

Ho SM, Leav I, Damassa D, Kwan PW, Merk FB \& Seto HS 1988 Testosterone-mediated increase in $5 \alpha$-dihydrotestosterone content, nuclear androgen receptor levels, and cell division in an androgenindependent prostate carcinoma of Noble rats. Cancer Research $\mathbf{4 8}$ 609-614.

Ho SM, Tang WY, Belmonte de Frausto J \& Prins GS 2006 Developmental exposure to estradiol and bisphenol A increases susceptibility to prostate carcinogenesis and epigenetically regulates phosphodiesterase type 4 variant 4 . Cancer Research 66 5624-5632. (doi:10.1158/ 0008-5472.CAN-06-0516)

Ho SM, Lee MT, Lam HM \& Leung YK 2011 Estrogens and prostate cancer: etiology, mediators, prevention, and management. Endocrinology and Metabolism Clinics of North America 40 591-614. (doi:10.1016/j.ecl. 2011.05.002)

Kuiper GG, Enmark E, Pelto-Huikko M, Nilsson S \& Gustafsson JA 1996 Cloning of a novel receptor expressed in rat prostate and ovary. PNAS 93 5925-5930. (doi:10.1073/pnas.93.12.5925)

Leav I, Ho SM, Ofner P, Merk FB, Kwan PW \& Damassa D 1988 Biochemical alterations in sex hormone-induced hyperplasia and dysplasia of the dorsolateral prostates of Noble rats. Journal of the National Cancer Institute 80 1045-1053. (doi:10.1093/jnci/80. 13.1045)

Leung YK, Mak P, Hassan S \& Ho SM 2006 Estrogen receptor (ER)- $\beta$ isoforms: a key to understanding ER- $\beta$ signaling. PNAS 103 13162-13167 (Erratum in: PNAS 2006103 14977). (doi:10.1073/ pnas.0605676103)

McNeal JE \& Bostwick DG 1986 Intraductal dysplasia: a premalignant lesion of the prostate. Human Pathology 17 64-71. (doi:10.1016) S0046-8177(86)80156-3) http://erc.endocrinology-journals.org DOI: 10.1530/ERC-14-0272
(C) 2014 Society for Endocrinology Printed in Great Britain 
Rohrmann S, Nelson WG, Rifai N, Brown TR, Dobs A, Kanarek N, Yager JD \& Platz EA 2007 Serum estrogen, but not testosterone, levels differ between black and white men in a nationally representative sample of Americans. Journal of Clinical Endocrinology and Metabolism 92 2519-2525. (doi:10.1210/jc.2007-0028)

Ross R, Bernstein L, Judd H, Hanisch R, Pike M \& Henderson B 1986 Serum testosterone levels in healthy young black and white men. Journal of the National Cancer Institute 76 45-48.
Yalow RS \& Berson SA 1960 Immunoassay of endogenous plasma insulin in man. Journal of Clinical Investigation 39 1157-1175. (doi:10.1172/ JCI104130)

Zhu X, Leav I, Leung YK, Wu M, Liu Q, Gao Y, McNeal JE \& Ho SM 2004 Dynamic regulation of estrogen receptor- $\beta$ expression by DNA methylation during prostate cancer development and metastasis. American Journal of Pathology 164 2003-2012. (doi:10.1016/S00029440(10)63760-1)

Received in final form 5 June 2014

Accepted 11 June 2014

Made available online as an Accepted Preprint

13 June 2014
Published by Bioscientifica Ltd. 